\title{
Differential Effects of High Glucose and Methylglyoxal on Viability and Polyol Metabolism in Immortalized Adult Mouse Schwann Cells
}

\author{
Kazunori Sango ${ }^{*}, 1$, Hiroko Yanagisawa ${ }^{1}$, Koichi Kato ${ }^{2}$, Noriaki Kato ${ }^{3}$, Hiroko Hirooka ${ }^{3}$ and \\ Kazuhiko Watabe $^{4}$
}

\begin{abstract}
Departments of ${ }^{1}$ Developmental Morphology and ${ }^{4}$ Molecular Neuropathology, Tokyo Metropolitan Institute for Neuroscience, Fuchu, Tokyo, Japan; ${ }^{2}$ Division of Endocrinology, Metabolism and Diabetology, Department of Internal Medicine, Aichi Medical University School of Medicine, Nagakute, Aichi, Japan, ${ }^{3}$ Pharmaceutical Research Laboratories, Sanwa Kagaku Kenkyusho Co. Ltd., Inabe, Mie, Japan
\end{abstract}

\begin{abstract}
Cultured Schwann cells under exposure to high glucose and methylglyoxal (MG) have been individually employed for studying diabetic neuropathy; however, similarities and differences between these two culture models have not been studied. We investigated the effects of high glucose and MG on viability, polyol pathway activity, and expression of oxidative stress markers (4-hydroxy-2-nonenal (4HNE), acrolein (ACR), and hexanoyl lysine (HEL)) in immortalized adult mouse Schwann cells (IMS32 cell line) in culture. Western blot and immunocytochemical analyses revealed that expression of aldose reductase (AR), 4HNE, ACR, and HEL in IMS32 was induced by exposure to both high glucose (30 $\mathrm{mM})$ and $\mathrm{MG}(0.5 \mathrm{mM})$ for $48 \mathrm{~h}$. Treatment with $\mathrm{MG}(0.1,0.2$, and $0.5 \mathrm{mM})$ induced cell death in a concentrationdependent manner, whereas high glucose environments $(30 \mathrm{mM}$ and $56 \mathrm{mM})$ did not impair cell viability. In contrast, intracellular sorbitol and fructose levels were significantly increased by high glucose, but not by MG. Taking these findings together, IMS32 cell line under high glucose conditions appears to be useful for studying oxidative stress in relation to the polyol pathway hyperactivity in diabetes. MG is capable of causing more detrimental damage to IMS32 than high glucose, but MG-induced upregulation of AR is unlikely to accelerate the polyol pathway activity.
\end{abstract}

Keywords: Diabetic neuropathy, immortalized Schwann cells, methylglyoxal, apoptotic cell death, oxidative stress markers, polyol pathway.

\section{INTRODUCTION}

In addition to retinopathy and nephropathy, peripheral neuropathy is one of the most common complications of diabetes mellitus. Although the pathogenesis of diabetic neuropathy remains largely unknown, metabolic alterations in cellular components (mainly neurons and Schwann cells) and microvascular abnormalities are thought to play major roles in its development [1]. Schwann cell abnormalities due to hyperglycemia can cause nerve dysfunction such as reduced nerve conduction velocity, axonal atrophy, and impaired axonal regeneration $[2,3]$. The role of Schwann cells in diabetic neuropathy is often discussed in relation to polyol pathway hyperactivity. Aldose reductase (AR: EC 1.1.1.21), the first enzyme in the polyol pathway, is localized to Schwann cells in the peripheral nerves [4], and the activation of $\mathrm{AR}$ and the subsequent accumulation of sorbitol in Schwann cells under hyperglycemic conditions can affect nerve functions through various mechanisms [1]. In addition to the accelerated polyol pathway, other consequences of hyperglycemia in Schwann cells (e.g., non-enzymatic glycation, oxidative stress, and impaired neurotrophin production) are likely to be involved in the development and progression of diabetic neuropathy [5].

*Address correspondence to this author at the Department of Developmental Morphology, Tokyo Metropolitan Institute for Neuroscience, 2-6 Musashidai, Fuchu, Tokyo 183-8526, Japan; Tel: 81-42-325-3881; Fax: 81-42-3218678; E-mail: sango-kz@igakuken.or.jp
Culture systems of Schwann cells appear to be useful for precise investigation of polyol pathway hyperactivity and other metabolic changes under diabetic conditions [6]. A cell line from rat Schwannoma, JS1 [7], and primary cultured adult rat Schwann cells [8] have been introduced to study polyol metabolism; however, these cells did not display intracellular sorbitol accumulation or enhanced AR expression and enzyme activity under high glucose $(25-30 \mathrm{mM})$ conditions, unless hyperosmotic stress (greater than $100 \mathrm{mM}$ ) was applied. In contrast to those studies, we recently observed increased AR expression and marked accumulation of sorbitol and fructose in an immortalized adult mouse Schwann cell line (IMS32) cultured under a high glucose $(30 \mathrm{mM})$ condition [9]. IMS32 showed distinct phenotypes of mature Schwann cells and gene expression profile similar to that of primary cultured Schwann cells; mRNA of neurotrophic factors (NGF, BDNF, NT-3, and GDNF) and polyol pathway-related enzymes (AR and SDH) were expressed in both IMS32 and cultured adult rat or mouse Schwann cells [10, 11]. High glucose environments up-regulate AR mRNA expression in IMS32 [9], but not in adult rat Schwann cells [11]. Thus, IMS32 culture under high glucose conditions is thought to be a suitable in vitro model for studying polyolpathway-related abnormalities in diabetes. Research suggests that high glucose conditions also influence viability and/or proliferation activity of cultured Schwann cells $[12,13]$. The oxidative damage induced by mitochondrial dysfunction under hyperglycemic conditions can activate the apoptotic cascade [14]; however, it is controversial whether hypergly- 
cemia is a potent inducer of apoptosis in cultured Schwann cells $[12,13]$. In addition to the exposure to high glucose environments, glycated products have been applied to Schwann cells for studying diabetic neuropathy [15-17]. Methylglyoxal (MG) is a reactive dicarbonyl precursor of advanced glycation end products (AGEs) and has been shown to induce apoptotic cell death of both primary cultured rat Schwann cells [16] and IMS32 [17]. The concentration of MG was found to increase in tissues and blood of streptozotocin-induced diabetic rats [18] and patients with diabetes [19]. Moreover, a recent clinical study by Beisswenger et al. [20] showed the correlation of the levels of plasma and urinary MG with the progression of diabetic nephropathy. These findings appear to suggest a possible involvement of MG in the pathogenesis of diabetic complications. Thus far, Schwann cells under exposure to high glucose and MG have been individually employed as in vitro models of diabetic neuropathy. However, similarities and differences between the two culture models have not been studied. In this study, we examined the effects of high glucose and MG on cell viability, expression of AR and oxidative stress markers (4-hydroxy-2-nonenal (4HNE), acrolein (ACR), and hexanoyl lysine (HEL)), and polyol metabolism in IMS32, and discussed the advantages and problems of these two culture models for studying diabetic neuropathy.

\section{MATERIALS AND METHODOLOGY}

\section{Cell Culture}

IMS32 cells were seeded into $75 \mathrm{~cm}^{2}$ flasks (Nalge Nunc International, Naperville, IL, USA) at a density of $2.5 \times$ $10^{4} / \mathrm{cm}^{2}$, and cultured in Dulbecco's Modified Eagle's medium (DMEM) (Sigma, St Louis, MO, USA) supplemented with $5 \%$ fetal calf serum [FCS] (Invitrogen, Groningen, Netherlands) at $37^{\circ} \mathrm{C}$ in an air $(95 \%) / \mathrm{CO}_{2}(5 \%)$ atmosphere. The medium contained $5.6 \mathrm{mM}$ glucose. When the cells reached confluency, they were detached from the flasks using $0.05 \%$ trypsin-EDTA (Invitrogen), and re-seeded into wells of 8-well chamber slides (Nalge Nunc), 6-well cell culture plates (Corning Inc., Corning, NY, USA), or 100-mm cell culture dishes (Nalge Nunc) at different cell densities. Cell counter plates (Watson Co. Ltd., Tokyo, Japan) were used for the calculation and adjustment of cell density. After incubation with the serum-containing medium for $48 \mathrm{~h}$, the cells were maintained in serum-free medium (DMEM and $\mathrm{N} 2$ supplement (Invitrogen)) containing $5.6 \mathrm{mM}$ glucose [Glc-5.6mM], $30 \mathrm{mM}$ glucose [Glc- $30 \mathrm{mM}$ ], or $0.5 \mathrm{mM} \mathrm{MG}$ (Sigma) [MG-0.5mM]. The serum-free media suppressed the proliferation of IMS32 and made it possible to maintain the cultures for up to 7 days without further detachment and reseeding of cells.

\section{Cell Viability Assay}

IMS32 were seeded into wells of 8-well chamber slides (Nalge Nunc) at four different cell densities $(2.5,1.2,0.8$, and $\left.0.5 \times 10^{4} / \mathrm{cm}^{2}\right)$. The cells were kept in each experimental condition ([Glc-5.6mM], [Glc-30mM], or [MG-0.5mM]) for 2 days, and then positive trypan blue staining under a phasecontrast microscope identified dead cells. The ratio (\%) of trypan-blue positive cells was expressed relative to the total number of cells counted (approximately 500 per well).
Detection of Apoptotic Cells by Terminal Deoxynucleotidyltransferase (TdT)-Mediated dUTP Nick end Labeling (TUNEL)

The cells were seeded into wells of 8-well chamber slides at a density of $0.5 \times 10^{4} / \mathrm{cm}^{2}$, and kept in each experimental condition for 2 and 7 days. Then the cells were fixed with $4 \%$ paraformaldehyde for $15 \mathrm{~min}$ at $4^{\circ} \mathrm{C}$. Apoptotic cells were detected by TUNEL using a commercial kit (Apoptosis detection system, Fluorescein; Promega, Madison, WI, USA) according to the manufacturer's instruction [21]. Prior to the detection, the cells were stained with $1 \mu \mathrm{g} / \mathrm{ml}$ propidium iodide (Sigma): propidium iodide stains both apoptotic and non-apoptotic cells red, while fluorescein-12-dUTP is incorporated in fragmented DNA, resulting in localized green fluorescence within the nuclei of apoptotic cells. The ratio (\%) of TUNEL-positive cells was expressed relative to the total number of cells counted (approximately 500 per well).

\section{Western Blotting}

The cells were seeded into $100-\mathrm{mm}$ cell culture dishes at a density of $2.5 \times 10^{4} / \mathrm{cm}^{2}$, and kept in each experimental condition for 2 days. Then the cells were rinsed with phosphate-buffered saline (PBS, Sigma) and detached from the flasks using cell scrapers (Sumitomo Bakelite Co. Ltd, Tokyo, Japan). These cells were suspended in $2 \mathrm{ml}$ of sterile water and collected in sterile tubes for use in Western blotting [22]. Protein was extracted from the cultured cells using lysis buffer $(10 \mathrm{mM}$ Tris, pH 7.4, $150 \mathrm{mM} \mathrm{NaCl}, 5 \mathrm{mM}$ EDTA, $1 \%$ Triton-X-100, 1\% NP40 and protease inhibitors: aprotinin, benzamidine, leupeptin, pepstatin A, PMSF). SDS-PAGE was performed using $10 \%$ polyacrylamide gel. After electrophoresis, the proteins were transferred onto a nitrocellulose membrane (Bio-Rad, Hercules, CA, USA) with an electro blotter (Nihon Eido Co., Ltd., Tokyo, Japan). The membrane was incubated for preblocking with a blotting solution (10 mM Tris, $\mathrm{pH} 7.4,150 \mathrm{mM} \mathrm{NaCl}, 5 \%$ skim milk, $2 \%$ bovine serum albumin and $0.1 \%$ Tween 20 ) for $2 \mathrm{~h}$ at room temperature, and then at $4^{\circ} \mathrm{C}$ overnight with the following antibodies:

1. goat anti-AR polyclonal antibody (ALR2 (P-20), 1: 2,000, Santa Cruz Biotech. Inc., Santa Cruz, CA, USA);

2. mouse anti-4HNE monoclonal antibody (1: 500, Nikken Seil Co., Ltd., Fukuroi, Japan); and

3. mouse anti- $\beta$-actin monoclonal antibody $(1: 1,000$, Sigma).

After rinsing with PBS, the membrane was incubated in a solution of horse radish peroxidase (HRP)-conjugated antigoat or anti-mouse $\operatorname{IgG}$ (1:2000, MBL, Nagoya, Japan) for 2 $\mathrm{h}$. After rinsing, immunocomplexes on the membrane were visualized with an ECL plus Western blotting detection kit (GE Healthcare Bio-Sciences Corp., Piscataway, NJ, USA).

\section{Immunocytochemistry}

The cells were seeded into wells of 8-well chamber slides at a density of $1-2 \times 10^{4} / \mathrm{cm}^{2}$. After 2 days of incubation in each experimental condition, the cells were fixed with $4 \%$ paraformaldehyde for $15 \mathrm{~min}$ at $4{ }^{\circ} \mathrm{C}$, and treated with $0.1 \%$ Triton X-100 in PBS for $5 \mathrm{~min}$ at room temperature. The 
fixed cells were incubated with the following antibodies (diluted with $20 \mathrm{mM}$ PBS containing $0.4 \%$ Block Ace (DS Pharma Biomedical Co., Ltd., Osaka, Japan)):

1. goat anti-AR polyclonal antibody (1: 3,000);

2. mouse anti-4HNE monoclonal antibody (1: 100);

3. mouse anti-acrolein (ACR) monoclonal antibody (1: 100, Nikken Seil);

4. mouse anti-hexanoyl lysine (HEL) monoclonal antibody (1: 100, Nikken Seil); and

5. rabbit anti-S100 polyclonal antibody (1: 3,000, DAKO, Carpinteria, CA, USA).

Since IMS32 is a murine Schwann cell line, a MOM immunodetection kit (Vector Laboratories Inc., Burlingame, CA, USA) was used for the reactions of mouse monoclonal antibodies (anti-4HNE, anti-ACR, and anti-HEL) according to the manufacturer's instruction. After rinsing with PBS, the cells were incubated for $1 \mathrm{~h}$ at $37^{\circ} \mathrm{C}$ with biotinylated antigoat IgG (for AR), anti-mouse IgG (for $4 \mathrm{HNE}, \mathrm{ACR}$, and HEL), or anti-rabbit IgG (for S100) antibody (1: 100, Vector Laboratories). After further incubation for $30 \mathrm{~min}$ at room temperature with avidin-biotin complex (Vector Laboratories), the immunoreaction was visualized under a light microscope using $0.01 \%$ diaminobenzidine tetrahydrochloride (DAB) (Wako Co., Tokyo, Japan) and $0.01 \%$ hydrogen peroxide in $50 \mathrm{mM}$ Tris buffer $(\mathrm{pH} 7.4)$ at room temperature for $15 \mathrm{~min}$.

\section{Measurement of the Intracellular Contents of Sorbitol and Fructose}

The cells were seeded into wells of 6-well plates (Corning Inc., Corning, NY, USA) at a density of $5 \times 10^{4} / \mathrm{cm}^{2}$ and kept in each experimental condition for 7 days. A subset of each sample was treated with $1 \mu \mathrm{M}$ of an AR inhibitor, SNK-
860 (Sanwa Kagaku Kenkyusho, Inabe, Japan) for 7 days. These culture conditions were termed [Glc-5.6mM/SNK], [Glc-30mM/SNK], and [MG-0.5mM/SNK]. Cells under each experimental condition were rinsed in ice-cold PBS and homogenized in $2 \mathrm{ml}$ of cold water with a cell sonicator. Protein concentrations were determined using a DC Protein Assay (Bio-Rad) according to the manufacturer's instructions. The polyol level in each lyophilized sample was determined as previously described [9].

\section{Statistical Analysis}

All data are expressed as means \pm S.E.M. Parametric comparisons between experimental groups were performed by one-way analysis of variance (ANOVA). When ANOVA showed a significant difference between groups $(\mathrm{P}<0.05)$, Bonferroni/Dunn test was used to identify which group differences accounted for the significant $P$ value.

\section{RESULTS}

\section{Viability of IMS32 was Affected by MG, But Not by High Glucose}

IMS32 cells were seeded at high $\left(2.5 \times 10^{4} / \mathrm{cm}^{2}\right.$ : Fig. 1AC) and low cell density $\left(0.5 \times 10^{4} / \mathrm{cm}^{2}\right.$ : Fig. 1D-F), and were kept in [Glc-5.6mM] (Fig. 1A, D), [Glc-30mM] (Fig. 1B, E), and $[\mathrm{MG}-0.5 \mathrm{mM}]$ (Fig. 1C, F) for 2 days. At the high cell density, a majority of the cells in each culture condition showed spindle-shaped morphology under phase-contrast microscopy, although we observed atrophic cells with roundshaped cell bodies more frequently in the presence of $\mathrm{MG}$ (Fig. 1C) than in the absence of MG (Fig. 1A, B). The number of atrophic cells was increased at the low cell density; however, a large proportion of the cells in [Glc-5.6mM] (Fig. 1D) and [Glc-30mM] (Fig. 1E) retained the spindle-shaped appearance. By contrast, more than a half of the cells in [MG-0.5mM] became atrophic (Fig. 1F). Consistent with the
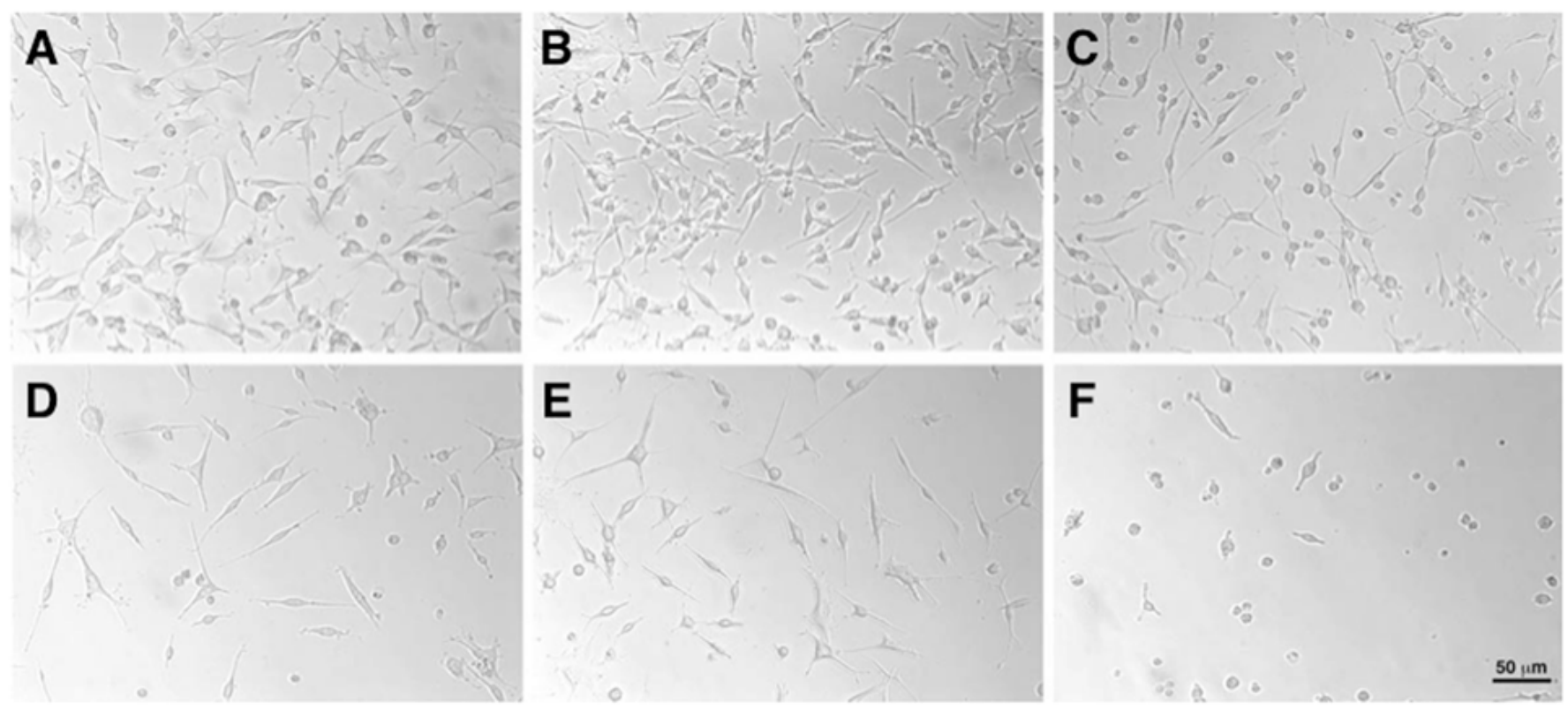

Fig. (1). Phase-contrast micrographs of IMS32 under [Glc-5.6mM] (A and D), [Glc-30mM] (B, E), and $[\mathrm{MG}-0.5 \mathrm{mM}](\mathbf{C}$ and F) at high (2.5 $\left.\times 10^{4} / \mathrm{cm}^{2}\right)(\mathbf{A}-\mathbf{C})$ and low cell density $\left(0.5 \times 10^{4} / \mathrm{cm}^{2}\right)(\mathbf{D}-\mathbf{F})$. Most of the cells under [Glc-5.6mM] and [Glc-30mM] at both high and low density showed spindle-shaped morphology, whereas cells with atrophic and round-shaped cell bodies were more frequently seen under [MG-0.5mM], especially at low cell density. 


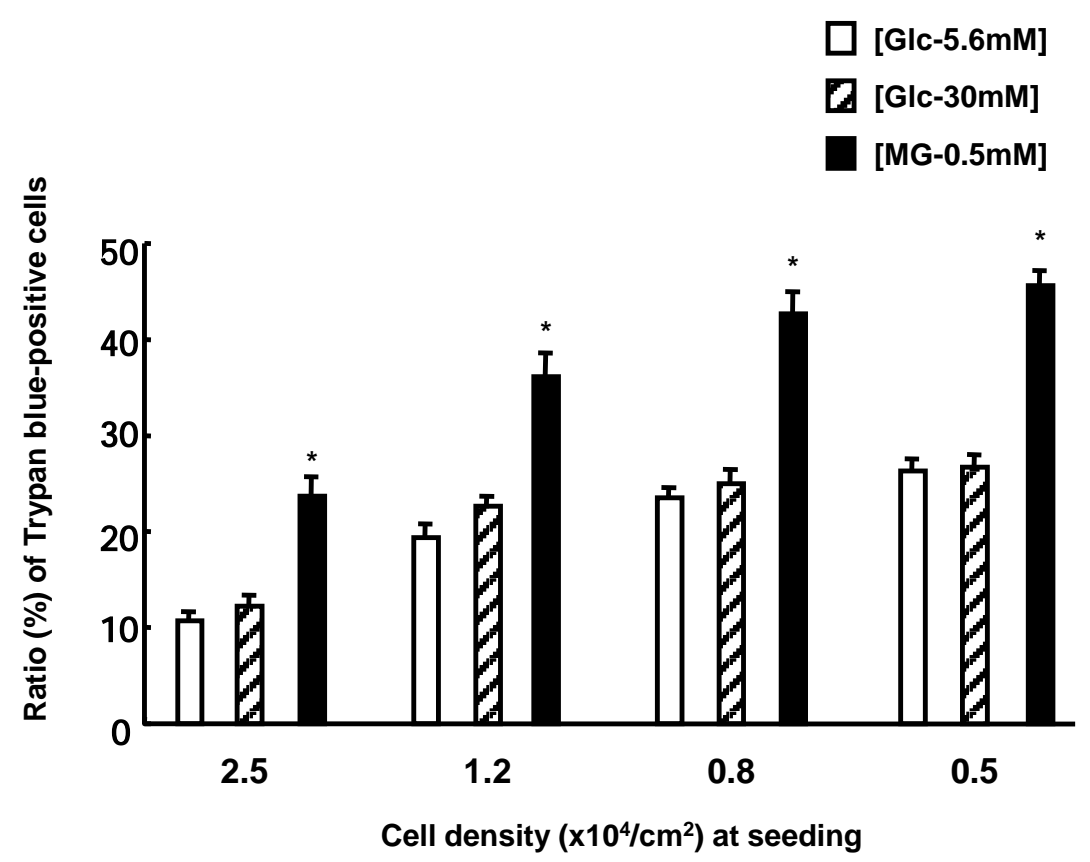

Fig. (2). Ratios (\%) of trypan-blue positive cells after 2 days exposure to [Glc-5.6mM], [Glc-30mM], and [MG-0.5mM] at four different cell densities. Values represent the mean + SEM of 6 experiments. $* \mathrm{P}<0.05$ as compared with [Glc-5.6mM] (by Bonferroni/Dunn post hoc analysis).

microscopic observations, the ratios (\%) of dead cells (identified as positive trypan blue staining) were significantly higher in $[\mathrm{MG}-0.5 \mathrm{mM}$ ] than in [Glc-5.6mM] and [Glc$30 \mathrm{mM}]$ at each cell density $\left(2.5,1.2,0.8\right.$, and $\left.0.5 \times 10^{4} / \mathrm{cm}^{2}\right)$ (Fig. 2). The percentages of dead cells in each culture condition tended to increase as the cell density declined. Apoptotic Cell Death was Induced by MG in a Dose-
Dependent Manner, But Not by High Glucose

The cell viability assay revealed that MG induced cell death, whereas high glucose did not. Next, we performed TUNEL assay to examine whether the exposure to high glucose and MG accelerated apoptotic cell death (Fig. 3). The
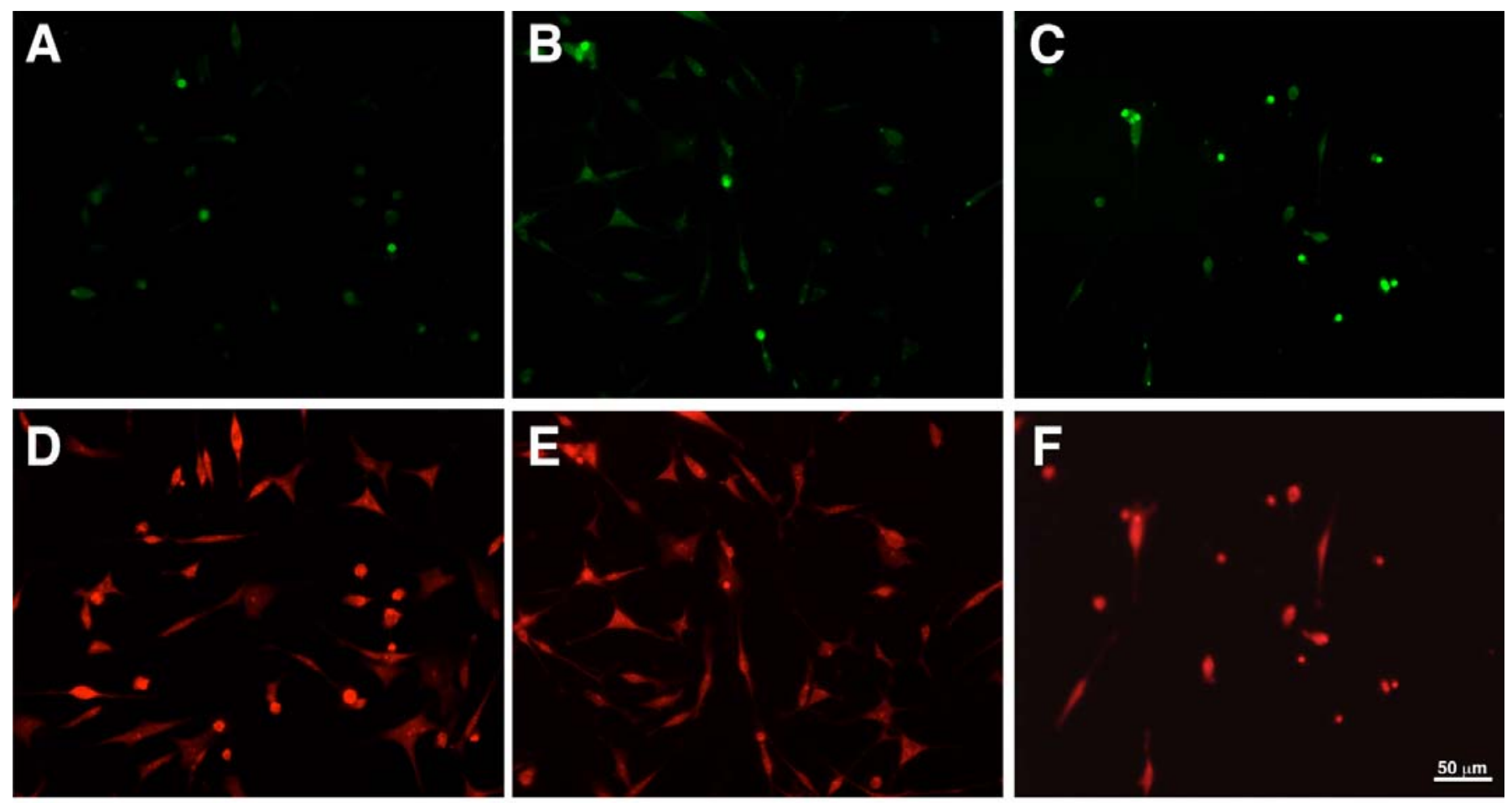

Fig. (3). Immunofluorescent micrographs (TUNEL stain) of IMS32 under [Glc-5.6mM] (A, D), [Glc-30mM] (B, E), and [MG-0.5mM] (C, F) at low cell density $\left(0.5 \times 10^{4} / \mathrm{cm}^{2}\right)$. Green fluorescence $(\mathbf{A}-\mathbf{C})$ was localized within the nuclei of apoptotic cells, whereas all cells were stained red with propidium iodide $(\mathbf{D}-\mathbf{F})$. 
ratios of TUNEL-positive cells after 2 and 7 days of incubation in $[\mathrm{MG}-0.5 \mathrm{mM}](41.8 \pm 4 \%$ and $51.3 \pm 3 \%)$ were significantly higher than those in [Glc-5.6mM] $(12.4 \pm 0.3 \%$ and $22.9 \pm 1.5 \%)$ and [Glc-30mM] $(15.6 \pm 1.9 \%$ and $27.5 \pm 1.1 \%)$ (Fig. 4). Further, we examined dose-response effects of glucose and $\mathrm{MG}$ on the apoptotic cell death. The increase in glucose concentration to $56 \mathrm{mM}$ slightly raised the percentages of TUNEL-positive cells $(28.3 \pm 1.8 \%$ after 7 days of incubation), but we observed no significant differences in the ratios between the normal and high glucose conditions. By contrast, the percentages of TUNEL-positive cells escalated as the MG concentration increased $(32.8 \pm 2.1 \%$ at $0.1 \mathrm{mM}$, $42.2 \pm 0.7 \%$ at $0.2 \mathrm{mM}$, and $51.3 \pm 3 \%$ at $0.5 \mathrm{mM}$ ), and each of these ratios was significantly higher than that in the absence of MG ([Glc-5.6mM]). These findings suggest that MGinduced cell death was dependent on the concentration of MG.

Treatment with an AR inhibitor, SNK-860, showed no significant effects on the percentages of TUNEL-positive cells in any culture condition (Fig. 5).

\section{Upregulated Expression of AR and Oxidative Stress Markers Under Exposure to Both High Glucose and MG}

By Western blot analysis with a monoclonal anti-4HNE antibody, the multiple expression bands were identified at the level of about $40,50,75$, and $150 \mathrm{kDa}$ in molecular size (Fig. 6, top), with more intense signals in [Glc-30mM] and [MG-0.5mM] than those in [Glc-5.6mM]. The multiple signals imply the formation of $4 \mathrm{HNE}$-protein conjugate in the cells [23]. The blot showed more intense signals for AR protein (a molecular size of about $36 \mathrm{kDa}$ ) in [Glc-30mM] and
[MG-0.5mM] than those in [Glc-5.6mM] (Fig. 6, middle), whereas there was no significant difference in the signal intensity to $\beta$-actin (a molecular size of about $42 \mathrm{kDa}$ ) among the 3 culture conditions (Fig. 6, bottom). The average values of relative expression of AR were 1 in [Glc-5.6mM], 1.53 in [Glc-30mM], and 2.23 in [MG-0.5mM], and those of 4-HNE (the bottom bands) were 1 in $[\mathrm{Glc}-5.6 \mathrm{mM}], 5.01$ in [Glc$30 \mathrm{mM}]$, and 12.34 in [MG-0.5mM], respectively.

Immunocytochemical analysis revealed that immunoreactivity for HEL (Fig. 7A-C), 4HNE (Fig. 7D-F), ACR (Fig. 7G-I), and AR (Fig. 7J-L) was more intense in [Glc-30mM] (Fig. 7B, E, H, K) and [MG-0.5mM] (Fig. 7C, F, I, L) than that in $[$ Glc-5.6mM] (Fig. 7A, D, G, J). The highest immunoreactivity was observed in $[\mathrm{MG}-0.5 \mathrm{mM}]$, where both spindle-shaped and atrophic cells were intensely stained. We saw no significant differences in immunoreactivity for S100 among the 3 culture conditions (Fig. 7M-O).

\section{Intracellular Polyol Levels Under Exposure to High Glu- cose and MG}

The intracellular contents of sorbitol and fructose were significantly higher in [Glc-30mM] (151.5 \pm 12.7 and $783.7 \pm 133.3 \mathrm{pmol} / \mathrm{mg})$ than those in $[\mathrm{Glc}-5.6 \mathrm{mM}](18.5 \pm 4.6$ and $62.1 \pm 7.3 \mathrm{pmol} / \mathrm{mg})$ and [MG-0.5mM] (20.9 \pm 5.6 and $52.2 \pm 26.2 \mathrm{pmol} / \mathrm{mg}$ ) (Fig. 8). The application of SNK-860 to [Glc-30mM] significantly reduced the contents of sorbitol from $151.5 \pm 12.7$ to $33.9 \pm 5.8 \mathrm{pmol} / \mathrm{mg}$, and fructose from $783.7 \pm 133.3$ to $360.7 \pm 84.6 \mathrm{pmol} / \mathrm{mg}$. SNK-860 had no effects on the polyol contents in $[\mathrm{Glc}-5.6 \mathrm{mM}]$ and [MG$0.5 \mathrm{mM}]$.

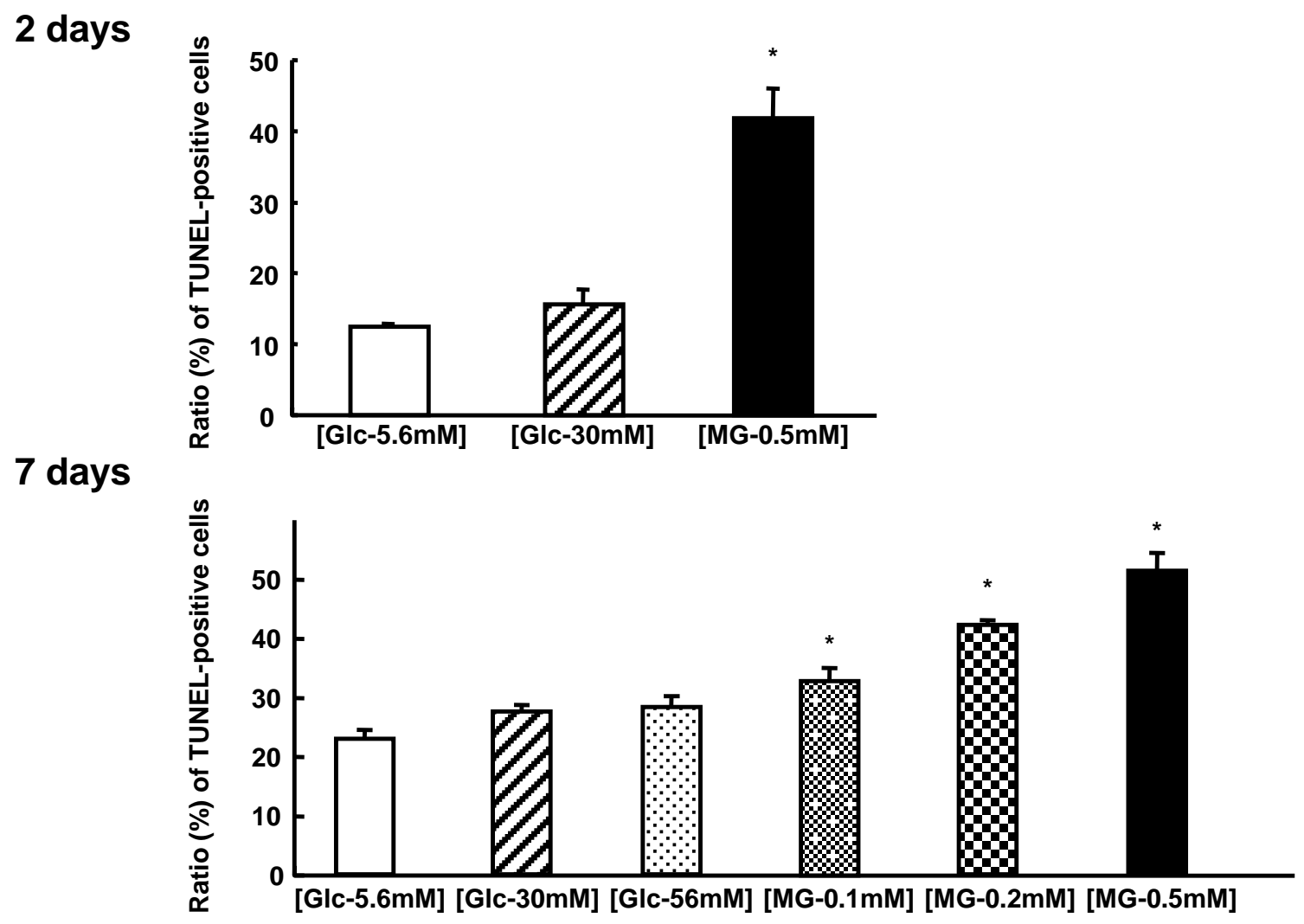

Fig. (4). Ratios (\%) of TUNEL-positive cells after 2 (upper panel) and 7 (lower panel) days of exposure to each culture condition at low cell density $\left(0.5 \times 10^{4} / \mathrm{cm}^{2}\right)$. Values represent the mean + SEM of 8 experiments. ${ }^{*} \mathrm{P}<0.05$ as compared with [Glc-5.6mM]. 


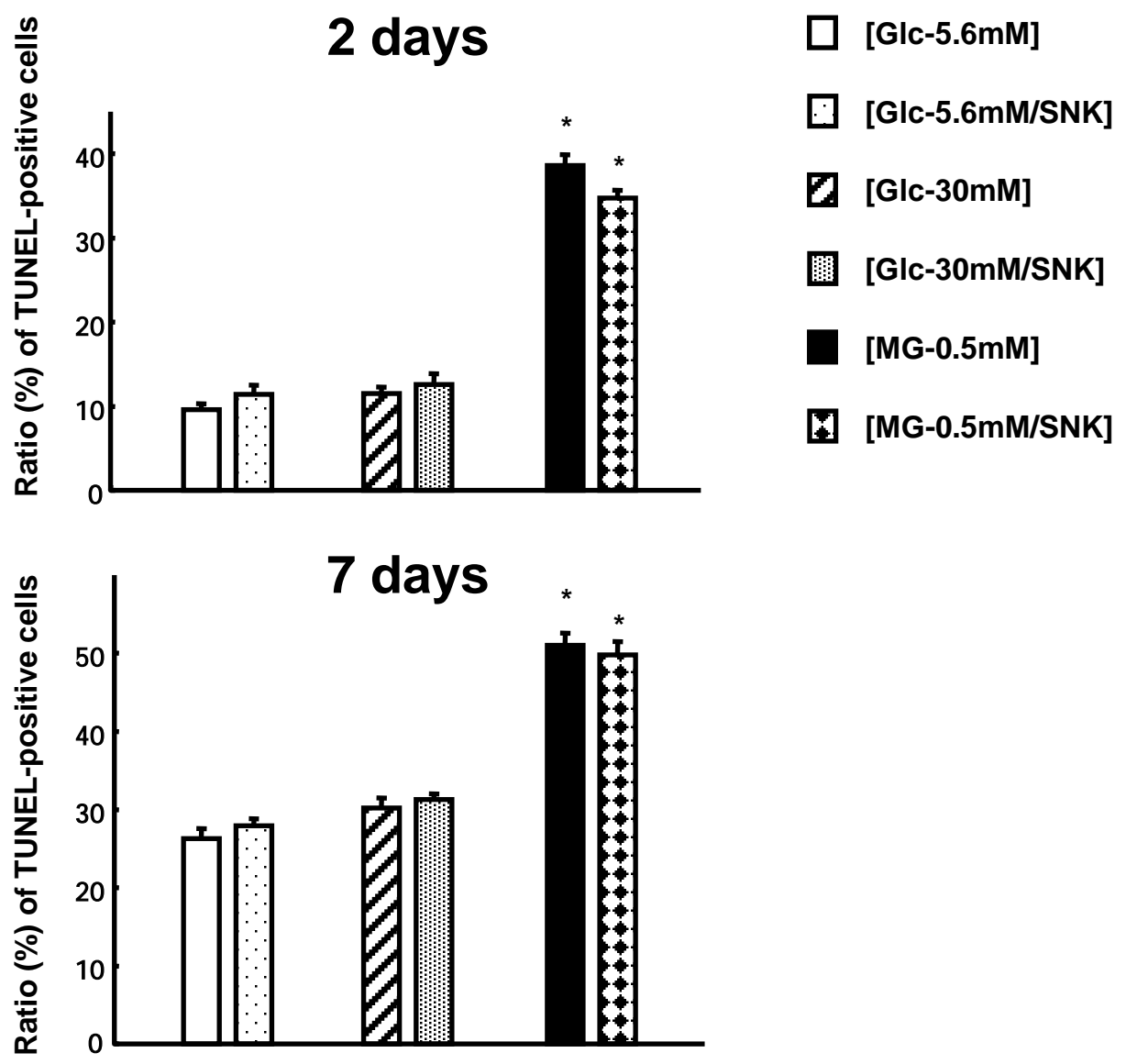

Fig. (5). An AR inhibitor, SNK-860, had no effects on ratios (\%) of TUNEL-positive cells after 2 (upper panel) and 7 (lower panel) days of exposure to each culture condition. Values represent the mean $+\mathrm{SEM}$ of 6 experiments. ${ }^{*} \mathrm{P}<0.05$ as compared with [Glc-5.6mM].

\section{DISCUSSION}

\section{MG is a Potent Inducer of Cell Death in IMS32, whereas High Glucose is Not}

Since the culture media employed in this study (DMEM supplemented with N2) lacked serum, Schwann cell survival factors such as neuregulins [24], and antioxidants (e.g., glutathione, vitamin E, superoxide dismutase, and catalase), the basal condition $([\mathrm{Glc}-5.6 \mathrm{mM}])$ itself does not appear to be a suitable environment for the survival of IMS32 cells. The viability assay revealed the cell-density dependence for survival after 2 days of exposure to [Glc-5.6mM]: nearly $90 \%$ of cells survived at the highest cell density $\left(2.5 \times 10^{4} / \mathrm{cm}^{2}\right.$ at seeding), whereas more than a quarter of cells died at the lowest density $\left(0.5 \times 10^{4} / \mathrm{cm}^{2}\right)$. These findings are consistent with those in a previous study with primary cultured Schwann cells [25], which suggested that autocrine survival factors are secreted from Schwann cells. It seems plausible that the increase in cell density augments production and availability of the autocrine factors, thereby leading to an improvement in viability. We have detected TGF- $\beta$ and galectin-1 immunoreactivity in the supernatants of IMS32 $[10,26]$. These factors promoted proliferation, migration, and/or stabilization of Schwann cells [27, 28], and may act as autocrine survival factors.

The percentages of TUNEL-positive cells under high glucose conditions ([Glc-30mM] and [Glc-56mM]) were slightly increased as compared with those under [Glc$5.6 \mathrm{mM}]$, but the changes were not significant. These findings, together with those in a previous study [13], are in contrast to the hypothesis of apoptotic response of Schwann cells to hyperglycemic conditions [12]. Oxidative damage induced by mitochondrial dysfunction under hyperglycemic conditions may trigger the apoptotic cascade [14]; however, the load of high glucose $(30-60 \mathrm{mM})$ on neurons and Schwann cells does not appear to be a sufficient inducer of cell death unless subjected to further insults [29]. Consistent with this idea, we failed to observe high glucose-induced apoptosis of IMS32 by employing MitoCapture ${ }^{\mathrm{TM}}$ mitochondrial apoptosis detection kit (BioVision, Mountain View, CA, USA), which could distinguish between healthy and apoptotic cells by detecting the changes in the mitochondrial membrane potential (Sango et al., personal data). It is noteworthy that ischemia-reperfusion injury to peripheral nerves of STZ-diabetic rats caused a marked increase in apoptotic Schwann cells [30]. In contrast to the load of high glucose, treatment with MG impaired viability of IMS32 in cell density- and concentration-dependent manners. MG is recognized to be a potent source of reactive oxygen species (ROS), and has been shown to induce apoptosis of neurons [31] and Schwann cells $[16,17]$. The findings from viability assays (trypan-blue exclusion and TUNEL) in this study suggest that MG-induced cell death involves apoptotic and necrotic events. Although the precise mechanism of 

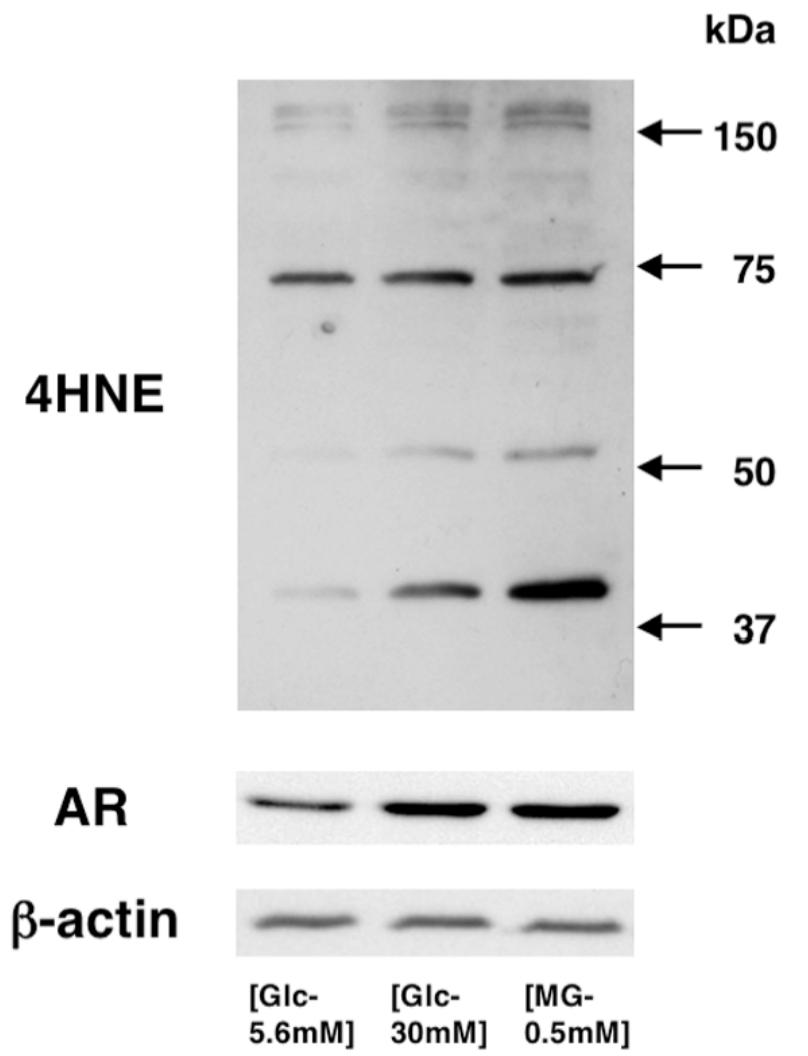

Fig. (6). High glucose- and MG-induced upregulation of $4 \mathrm{HNE}$ and AR by Western blot analysis. The blot incubated with a monoclonal anti-4HNE antibody (top) shows 5 major expression bands in each experimental group, with more intense signals in [Glc-30mM] and [MG-0.5mM] than in [Glc-5.6mM]. Marker molecular masses for calibration are indicated on the left. The blot incubated with a polyclonal anti-AR antibody (middle) showed more intense signals (about $36 \mathrm{kDa}$ in molecular size) in [Glc-30mM] and [MG-0.5mM] than in $[\mathrm{Glc}-5.6 \mathrm{mM}]$. The blot incubated with a monoclonal anti- $\beta$ actin antibody (bottom) showed that there was no significant difference in the intensity of signals (about $42 \mathrm{kDa}$ in molecular size) among each experimental group. We observed similar expression patterns in 3 experiments with different cell samples. The average values of relative expression (band intensity) of AR were 1 in [Glc$5.6 \mathrm{mM}], 1.53$ in [Glc-30mM], and 2.23 in [MG-0.5mM], and those of 4-HNE (the bottom bands) were 1 in [Glc-5.6mM], 5.01 in [Glc$30 \mathrm{mM}]$, and 12.34 in [MG-0.5mM], respectively.

Schwann cell death under exposure to MG remains unknown, research suggests that the signaling pathways through the activation of the mitogen-activated protein kinases (MAPK) (p38 MAPK [16] and c-Jun N-terminal kinase (JNK) [17]) are involved in the apoptotic reactions. We observed that treatment with C-peptide induced phosphorylation of ERK and ameliorated impaired proliferation of IMS32 under high glucose conditions (Kato et al., unpublished data). This finding suggests that insufficient MAPK signaling under diabetic state might be associated with decreased proliferative activity of IMS32, although further studies are needed to clarify this. In contrast, the MAPK signaling activated by MG could lead to Schwann cell death. In a recent report by de Arriba et al. [31], MG decreased mitochondrial membrane potential and intracellular ATP levels in SH-SY5Y neuroblastoma cells. This finding suggests that impaired mitochondrial respiration and energy depletion may be, at least in part, responsible for MG-induced cell death.

The Western blot and immunocytochemical analyses revealed that both high glucose and $\mathrm{MG}$ induced expression of oxidative stress markers such as 4HNE, ACR, and HEL. Research suggests that $4 \mathrm{HNE}$ and ACR (2-propenal), the most toxic byproducts of lipid peroxidation, are involved in the pathogenesis of neurodegenerative diseases [32] and traumatic nerve injury [33]. 4HNE, one of the 4-hydroxyalkenals generated from hydroxyperoxides, can bind to histidine, lysine, and cysteine residues of various proteins, thereby altering the protein structure and function. Obrosova et al. [34] observed increased concentrations of 4-hydroxyalkenals in sciatic nerves of STZ-diabetic rats. In a recent study by Fernyhough and Zherebitskaya (Society for Neuroscience 2007, San Diego), 4HNE was localized in the dystrophic swellings of regenerating axons from diabetic rat sensory neurons. ACR is more reactive than $4 \mathrm{HNE}$, and has exerted neurotoxic activities on cultured hippocampal neurons [35]. The induction of ACR in the retina [36] and kidney [37] under diabetic state suggests its involvement in the development and/or progression of diabetic complications. HEL, a novel lipid hydroperoxide-modified lysine residue, is thought to be a useful biomarker for the initial stage of lipid peroxidation [38]. The urinary HEL from patients with diabetes was significantly higher than that from non-diabetics [39], but there has been no direct evidence to show implications of HEL in diabetic neuropathy or other complications. The findings in this study suggest that both high glucose and MG can accelerate the reactions of lipid peroxidation and the production of the oxidative stress markers (4HNE, ACR, and HEL) in Schwann cells. However, it appears that the oxidative damage induced by MG is more detrimental to Schwann cells than that induced by high glucose.

\section{MG Induces AR Expression, But Does Not Accelerate the Polyol Pathway in IMS32}

Although a considerable number of studies have investigated the pathological role of AR and the polyol pathway in the development of diabetic complications, less attention has been paid to the physiological functions of AR (i.e., osmoregulation, aldehyde detoxification, and steroid and catecholamine metabolism) [40]. In particular, AR and other aldo-keto reductases catalyze the reduction of reactive biogenic aldehydes [41]. The upregulation of AR expression under exposure to $\mathrm{MG}$ in Schwann cells (the present study) and aortic smooth muscle cells [42] indicates that MG is a preferred substrate for AR. In contrast, the intracellular sorbitol and fructose contents were markedly increased by high glucose, but not by MG. It seems reasonable to suppose that the amount of glucose available for utilization through the polyol pathway under normoglycemic conditions is insufficient to cause sorbitol accumulation even though AR expression is increased. However, several studies have shown AR activation followed by increase in the polyol pathway activity in normoglycemic environments. For instance, nondiabetic rat hearts subjected to ischemia-reperfusion ex vivo and in situ (coronary ligation) displayed enhanced AR activity and myocardial sorbitol accumulation [43]. Hyperosmotic stress is also known to cause AR activation and sorbitol 


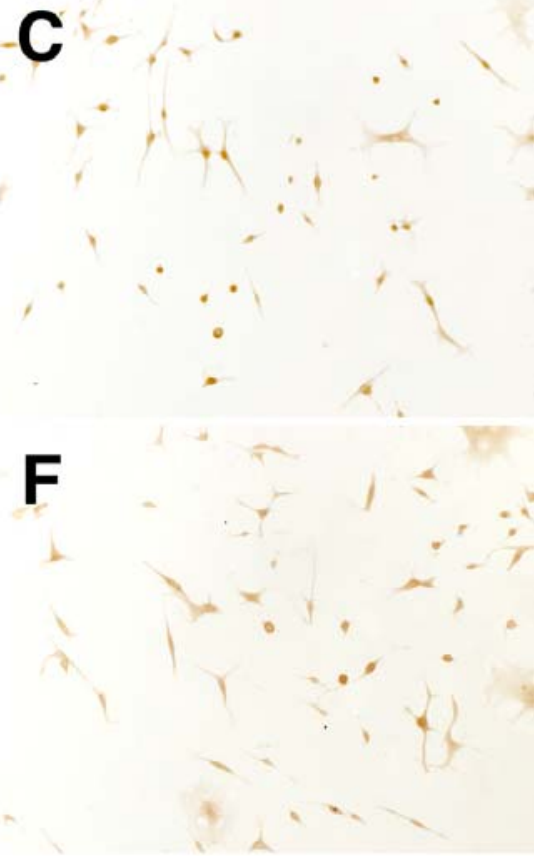

G

H

$\mathbf{J}$

I

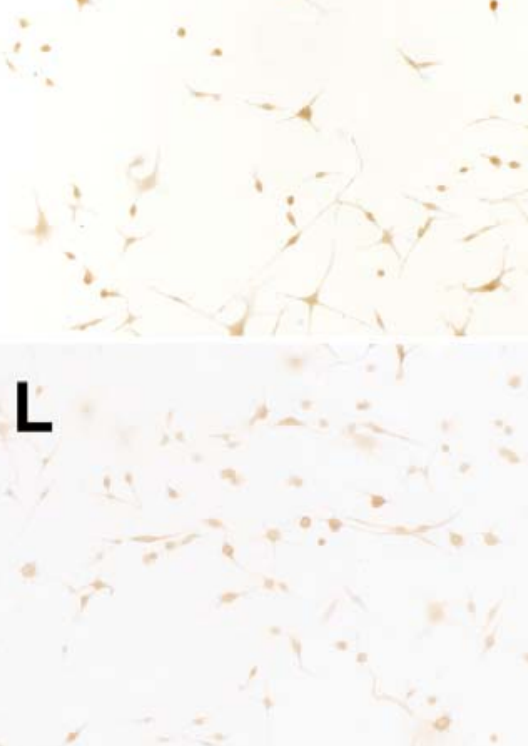

M

$\mathbf{N}$

0

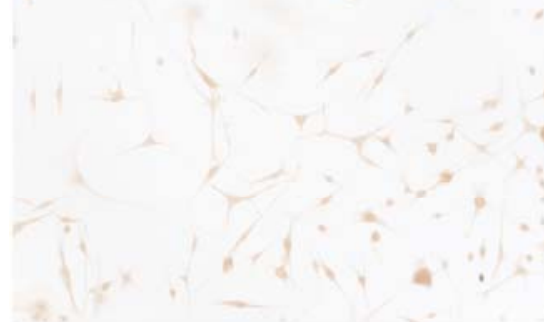

N

Fig. (7). High glucose- and MG-induced upregulation of HEL (A-C), 4HNE (D-F), ACR (G-I), and AR (J-L) in IMS32 by immunocytochemistry. The photomicrographs showed more intense immunoreactivity for each marker in [Glc-30mM] (B, E, H, K) and $[\mathrm{MG}-0.5 \mathrm{mM}]$ $(\mathbf{C}, \mathbf{F}, \mathbf{I}, \mathbf{L})$ than that in $[\mathrm{Glc}-5.6 \mathrm{mM}](\mathbf{A}, \mathbf{D}, \mathbf{G}, \mathbf{J})$. Note the intense immunoreactivity for both spindle-shaped and round-shaped cells in [MG-0.5mM]. We observed no significant difference in the immunoreactivity to S100 between [Glc-5.6mM] (M) and [Glc-30mM] (N) or $[\mathrm{MG}-0.5 \mathrm{mM}](\mathbf{O})$. 

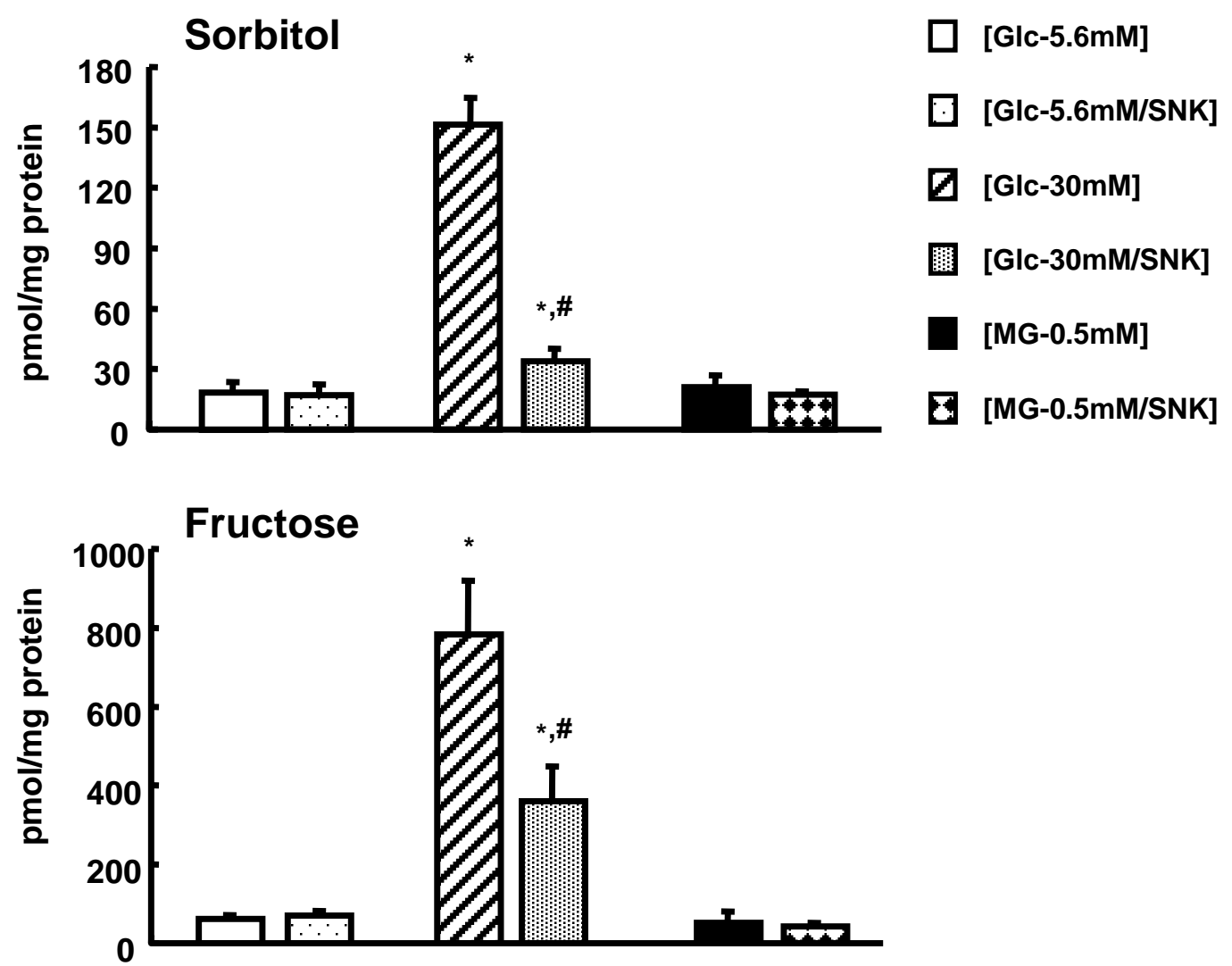

Fig. (8). Intracellular contents of sorbitol (upper panel) and fructose (lower panel) after 7 days of exposure to [Glc-5.6mM], [Glc-30mM], and $[\mathrm{MG}-0.5 \mathrm{mM}]$ in the presence or absence of SNK-860 $(1 \mu \mathrm{M})$. Values represent the mean $+\mathrm{SEM}$ of 6 experiments. $* \mathrm{P}<0.01$ as compared with $[\mathrm{Glc}-5.6 \mathrm{mM}]$ and $\# \mathrm{P}<0.01$ as compared with [Glc-30mM].

accumulation in a variety of cells [8, 44]. These findings suggest that AR induced by the ischemic and hyperosmotic insults can participate in the polyol metabolism, although the precise mechanisms for the acceleration of glucose uptake and/or utilization as a substrate for AR under those nondiabetic conditions remain unclear. In contrast to those insults, the exposure to $\mathrm{MG}$ is unlikely to activate the polyol pathway. Considering that AR is a detoxification enzyme that degrades reactive aldehydes, the MG-induced AR upregulation in Schwann cells appears to be a consequence of cytoprotective reactions, rather than a pathological event associated with the polyol pathway hyperactivity. However, the efficacy of MG detoxification through AR upregulation in IMS32 is thought to be insufficient to prevent cell death.

Treatment with AR inhibitors (Sorbinil and Ponalrestat) augmented the cytotoxic effects of reactive aldehydes in cultured smooth muscle cells [45] and lens epithelial cells [46]. These findings provide evidence to support the protective role of AR against the cytotoxic aldehydes in normoglycemic conditions. In contrast to those studies, treatment with SNK-860 did not exacerbate the MG-induced Schwann cell death in this study. This may be due to the complex metabolic disposal system of MG; several enzymes other than AR (e.g., aldehyde reductase (AHR), aldehyde dehydrogenases, and glutathione-dependent glyoxalase system) can also catalyze MG detoxification $[47,48]$. In addition, SNK-860 has exerted more selective inhibition of AR with less effect on the activities of AHR than other AR inhibitors [49]. The results in our previous study suggest that AR inhibition by
SNK-860 may upregulate AHR to be more active against the toxic substances [9]. Further investigations are needed to elucidate the role of AR in the detoxification of carbonylcontaining compounds.

\section{CONCLUSION}

Cultured Schwann cells under exposure to high glucose and MG have been individually employed as in vitro models to study diabetic neuropathy. The present study with immortalized adult mouse Schwann cells (IMS32 cell line) revealed the following similarities and differences between the two culture models:

1. both high glucose and $\mathrm{MG}$ induced upregulation of AR and the oxidative stress markers (4HNE, ACR, and HEL);

2. MG induced cell death in cell density- and dosedependent manners, whereas high glucose did not; and

3. high glucose increased intracellular contents of sorbitol and fructose, whereas MG did not.

The IMS32 culture under high glucose conditions appears to be useful for studying oxidative stress in relation to the polyol pathway hyperactivity in diabetes. By contrast, growing evidence against the hypothesis of diabetesassociated neuronal and Schwann cell death has made it problematic to use the Schwann cell culture under exposure to $\mathrm{MG}$ for studying diabetic neuropathy. However, the MG- 
exposed culture may be valuable to elucidate functional roles of AR in the detoxification of reactive aldehydes.

\section{ABBREVIATIONS}

$\mathrm{ACR}=$ Acrolein
$\mathrm{AHR}=$ Aldehyde reductase
$\mathrm{AR}=$ Aldose reductase
$\mathrm{FCS}=$ Fetal calf serum
$\mathrm{HEL}=$ Hexanoyl lysine
$4 \mathrm{HNE}=4$-Hydroxy-2-nonenal
$\mathrm{MG}=$ Methylglyoxal
$\mathrm{SDH}=$ Sorbitol dehydrogenase
$\mathrm{TUNEL}=$ Deoxynucleotidyltransferase (TdT)-mediated

\section{ACKNOWLEDGEMENTS}

This work was supported by a Grant-in-aid for Scientific Research from the Japanese Ministry of Education, Science, Sports and Culture [Kakenhi 19500337], grants from Sanwa Kagaku Kenkyusho, and the Umehara Fund of Yokohama Foundation for the Advancement of Medical Science (Yokohama, Japan). We thank Drs. Hitoshi Kawano, Masaharu Hayashi, and Tadao Sakai for their helpful suggestions, and Drs. Naoyuki Tanuma, Shizuka Takaku and Takeshi Suzuki for their technical comments.

\section{REFERENCES}

[1] Tomlinson DR, Gardiner NJ. Glucose neurotoxicity. Nat Rev Neurosci 2008; 9: 36-45.

[2] Song Z, Fu DT, Chan YS, Leung S, Chung SS, Chung SK. Transgenic mice overexpressing aldose reductase in Schwann cells show more severe nerve conduction velocity deficit and oxidative stress under hyperglycemic stress. Mol Cell Neurosci 2003; 23: 638-47.

[3] Yasuda H, Terada M, Maeda K, et al. Diabetic neuropathy and nerve regeneration. Prog Neurobiol 2003; 69: 229-85.

[4] Kern TS, Engerman RL. Immunohistochemical distribution of aldose reductase. Histochem J 1982; 14: 507-15.

[5] Eckersley L. Role of the Schwann cell in diabetic neuropathy. Int Rev Neurobiol 2002; 50: 293-321.

[6] Sango K, Saito H, Takano M, Tokashiki A, Inoue S, Horie H. Cultured adult animal neurons and Schwann cells give us new insights into diabetic neuropathy. Curr Diabetes Rev 2006; 2: 169-83.

[7] Mizisin AP, Li L, Perello M, et al. Polyol pathway and osmoregulation in JS1 Schwann cells grown in hyperglycemic and hyperosmotic conditions. Am J Physiol 1996; 270: F90-97.

[8] Suzuki T, Mizuno K, Yashima S, et al. Characterization of polyol pathway in Schwann cells isolated from adult rat sciatic nerves. J Neurosci Res 1999; 57: 495-503.

[9] Sango K, Suzuki T, Yanagisawa H, et al. High glucose-induced activation of the polyol pathway and changes of gene expression profiles in immortalized adult mouse Schwann cells IMS32. J Neurochem 2006; 98: 446-58

[10] Watabe K, Fukuda T, Tanaka J, Honda H, Toyohara K, Sakai O. Spontaneously immortalized adult mouse Schwann cells secrete autocrine and paracrine growth-promoting activities. J Neurosci Res 1995; 41: 279-90.

[11] Maekawa K, Tanimoto T, Okada S, Suzuki T, Suzuki T, YabeNishimura C. Expression of aldose reductase and sorbitol dehydrogenase genes in Schwann cells isolated from rat: effects of high glucose and osmotic stress. Brain Res Mol Brain Res 2001; 87: 251-6.

[12] Delaney CL, Russell JW, Cheng HL, Feldman EL. Insulin-like growth factor-I and over-expression of Bcl-xL prevent glucosemediated apoptosis in Schwann cells. J Neuropathol Exp Neurol 2001; 60: 147-60.
[13] Gumy LF, Bampton ET, Tolkovsky AM. Hyperglycaemia inhibits Schwann cell proliferation and migration and restricts regeneration of axons and Schwann cells from adult murine DRG. Mol Cell Neurosci 2008; 37: 298-311.

[14] Nishikawa T, Araki E. Impact of mitochondrial ROS production in the pathogenesis of diabetes mellitus and its complications. Antioxid Redox Signal 2007; 9: 343-53.

[15] Sekido H, Suzuki T, Jomori T, Takeuchi M, Yabe-Nishimura C, Yagihashi S. Reduced cell replication and induction of apoptosis by advanced glycation end products in rat Schwann cells. Biochem Biophys Res Commun 2004; 320: 241-8.

[16] Fukunaga M, Miyata S, Liu BF, et al. Methylglyoxal induces apoptosis through activation of p38 MAPK in rat Schwann cells. Biochem Biophys Res Commun 2004; 320: 689-95.

[17] Ota K, Nakamura J, Li W, et al. Metformin prevents methylglyoxal-induced apoptosis of mouse Schwann cells. Biochem Biophys Res Commun 2007; 357: 270-5.

[18] Phillips SA, Mirrlees D, Thornalley PJ. Modification of the glyoxalase system in streptozotocin-induced diabetic rats. Effect of the aldose reductase inhibitor Statil. Biochem Pharmacol 1993; 46: 805-11.

[19] McLellan AC, Thornalley PJ, Benn J, Sonksen PH. Glyoxalase system in clinical diabetes mellitus and correlation with diabetic complications. Clin Sci (Lond) 1994; 87: 21-29.

[20] Beisswenger PJ, Drummond KS, Nelson RG, Howell SK, Szwergold BS, Mauer M. Susceptibility to diabetic nephropathy is related to dicarbonyl and oxidative stress. Diabetes 2005; 54: 3274-81.

[21] Sango K, Horie H, Saito H, et al. Diabetes is not a potent inducer of neuronal cell death in mouse sensory ganglia, but it enhances neurite regeneration in vitro. Life Sci 2002; 71: 2351-68.

[22] Sango K, Yanagisawa H, Takaku S. Expression and histochemical localization of ciliary neurotrophic factor in cultured adult rat dorsal root ganglion neurons. Histochem Cell Biol 2007; 128: 35-43.

[23] Malecki A, Garrido R, Mattson MP, Hennig B, Toborek M. 4Hydroxynonenal induces oxidative stress and death of cultured spinal cord neurons. J Neurochem 2000; 74(6): 2278-87.

[24] Syroid DE, Maycox PR, Burrola PG, et al. Cell death in the Schwann cell lineage and its regulation by neuregulin. Proc Natl Acad Sci USA 1996; 93: 9229-34

[25] Cheng L, Esch FS, Marchionni MA, Mudge AW. Control of Schwann cell survival and proliferation: autocrine factors and neuregulins. Mol Cell Neurosci 1998; 12: 141-56.

[26] Sango K, Tokashiki A, Ajiki K, et al. Synthesis, localization and externalization of galectin-1 in mature dorsal root ganglion neurons and Schwann cells. Eur J Neurosci 2004; 19: 55-64.

[27] Day WA, Koishi K, McLennan IS. Transforming growth factor $\beta 1$ may regulate the stability of mature myelin sheath. Exp Neurol 2003; 184: 857-64.

[28] Horie H, Kadoya T, Hikawa N, et al. Oxidized galectin-1 stimulates macrophages to promote axonal regeneration in peripheral nerves after axotomy. J Neurosci 2004; 24: 1873-80.

[29] Kogawa S, Yasuda H, Terada M, Maeda K, Kikkawa R. Apoptosis and impaired axonal regeneration of sensory neurons after nerve crush in diabetic rats. Neuroreport 2000; 11: 663-7.

[30] Wang Y, Schmeichel AM, Iida H, Schmelzer JD, Low PA. Ischemia-reperfusion injury causes oxidative stress and apoptosis of Schwann cell in acute and chronic experimental diabetic neuropathy. Antioxid Redox Signal 2005; 7: 1513-20.

[31] de Arriba SG, Stuchbury G, Yarin J, Burnell J, Loske C, Münch G. Methylglyoxal impairs glucose metabolism and leads to energy depletion in neuronal cells - protection by carbonyl scavengers. Neurobiol Aging 2007; 28: 1044-50.

[32] Florang VR, Rees JN, Brogden NK, Anderson DG, Hurley TD, Doorn JA. Inhibition of the oxidative metabolism of 3,4dihydroxyphenylacetaldehyde, a reactive intermediate of dopamine metabolism, by 4-hydroxy-2-nonenal. Neurotoxicology 2007; 28: 76-82.

[33] Luo J, Uchida K, Shi R. Accumulation of acrolein-protein adducts after traumatic spinal cord injury. Neurochem Res 2005; 30: 291-5.

[34] Obrosova IG, Fathallah L, Stevens MJ. Taurine counteracts oxidative stress and nerve growth factor deficit in early experimental diabetic neuropathy. Exp Neurol 2001; 172: 211-9.

[35] Lovell MA, Xie C, Markesbery WR. Acrolein is increased in Alzheimer's disease brain and is toxic to primary hippocampal cultures. Neurobiol Aging 2001; 22: 187-94. 
[36] Schaefer S, Kajimura M, Tsuyama S, et al. Aberrant utilization of nitric oxide and regulation of soluble guanylate cyclase in rat diabetic retinopathy. Antioxid Redox Signal 2003; 5: 457-65.

[37] Suzuki D, Miyata T, Saotome N, et al. Immunohistochemical evidence for an increased oxidative stress and carbonyl modification of proteins in diabetic glomerular lesions. J Am Soc Nephrol 1999; 10: 822-32.

[38] Kato Y, Mori Y, Makino Y, et al. Formation of N-epsilon(hexanonyl)lysine in protein exposed to lipid hydroperoxide. A plausible marker for lipid hydroperoxide-derived protein modification. J Biol Chem 1999; 274: 20406-14.

[39] Osawa T, Kato Y. Protective role of antioxidative food factors in oxidative stress caused by hyperglycemia. Ann NY Acad Sci 2005; 1043: 440-51.

[40] Yabe-Nishimura C. Aldose reductase in glucose toxicity: A potential target for the prevention of diabetic complications. Pharmacol Rev 1998; 50: 21-33.

[41] Rittner HL, Hafner V, Klimiuk PA, Szweda LI, Goronzy JJ, Weyand CM. Aldose reductase functions as a detoxification system for lipid peroxidation products in vasculitis. J Clin Invest 1999; 103: 1007-13.

[42] Chang KC, Paek KS, Kim HJ, Lee YS, Yabe-Nishimura C, Seo HG. Substrate-induced up-regulation of aldose reductase by methylglyoxal, a reactive oxoaldehyde elevated in diabetes. Mol Pharmacol 2002; 61: 1184-91.
[43] Kaiserova K, Tang XL, Srivastava S, Bhatnagar A. Role of nitric oxide in regulating aldose reductase activation in the ischemic heart. J Biol Chem 2008; 283: 9101-12.

[44] Galvez AS, Ulloa JA, Chiong M, et al. Aldose reductase induced by hyperosmotic stress mediates cardiomyocyte apoptosis: Differential effects of sorbitol and mannitol. J Biol Chem 2003; 278: 38484-94.

[45] Spycher SE, Tabataba-Vakili S, O’Donnell VB, Palomba L, Azzi A. Aldose reductase induction: A novel response to oxidative stress of smooth muscle cells. FASEB J 1997; 11: 181-8.

[46] Pladzyk A, Reddy AB, Yadav UC, Tammali R, Ramana KV, Srivastava SK. Inhibition of aldose reductase prevents lipopolysaccharide-induced inflammatory response in human lens epithelial cells. Invest Ophthalmol Vis Sci 2006; 47: 5395-403.

[47] Suzuki K, Koh YH, Mizuno H, Hamaoka R, Taniguchi N. Overexpression of aldehyde reductase protects $\mathrm{PC} 12$ cells from cytotoxicity of methylglyoxal or 3-deoxyglucosone. J Biochem 1998; 123: 353-7.

[48] Vander Jagt DL, Hunsaker LA. Methylglyoxal metabolism and diabetic complications: Roles of aldose reductase, glyoxalase-I, betaine aldehyde dehydrogenase and 2-oxoaldehyde dehydrogenase. Chem Biol Interact 2003; 143-144: 341-51.

[49] Mizuno K, Suzuki T, Tanaka T, Taniko K, Suzuki T. Inhibitory effects of fidarestat on aldose reductase and aldehyde reductase activity evaluated by a new method using HPLC with post-column spectrophotometric detection. Biol Pharm Bull 2000; 23: 244-8. 